DOI https://doi.org/10.30525/978-9934-588-80-8-2.32

\title{
VR - FUTURE OF FOREIGN LANGUAGE TEACHING: PROSPECTS OF THE NON-DISTANT FUTURE
}

\author{
Voloshok K. V. \\ Junior Research Fellow of Research and Training Linguistic Center \\ Ivan Kozhedub Kharkiv National Air Force University \\ Stakhova M. O. \\ Research Fellow of Research and Training Linguistic Center \\ Ivan Kozhedub Kharkiv National Air Force University \\ Kharkiv, Ukraine
}

Nowadays, virtual reality-based technologies are widely used in many spheres of our life. Although the main part of its usage is entertainment, VR is in its adoption stage into many other ways of applying. Therapeutic approaches that involve art, teaching tactics in sports, medical and cognitive rehabilitation are only some of them. VR is also widely used in educational purposes, but mostly in medical and military training. Meanwhile, some advantages of VR let us believe in its vast application in the field of education [1].

During the education process, complexity of some tasks and concepts can cause problems for students. Modern educational units eliminate those difficulties by using new technology-based tools that help meet the needs of the diverse student population. Virtual Reality plays an important role in teaching process, providing an interesting and engaging way of learning. It is a powerful aid, in terms of supporting and facilitating learning and teaching processes.

Most important features of virtual reality technology are feeling of presence, high degree of realism, dynamic environment and an opportunity to learn online and offline [3].

\section{Feeling of presence and high degree of realism}

One of the main peculiarities of VR is feeling of presence. Slater and Wilbur describe presence as the feeling of «being there». Basically, it happens when user wears on a headset, that consists of head mounted display. Another way to achieve feeling of presence is through specially designed rooms with multiple large screens. Being completely involved in the learning process can motivate students to receive new information from remote locations worldwide [1].

High degree of realism and believability can make a huge difference in the learning process. It is often achieved with the help of 360 degrees-view and the 3D model of the environment [2]. 
There is always a possibility to duplicate a known environment, like a classroom, or even creating a new one. New three - dimensional artificial world encourages learners' curiosity and boosts their will and motivation to know more and more about it.

\section{Dynamic environment}

VR is especially effective when it comes to allowing students to experience new worlds where they can develop resources for problem solving and, ultimately, view the environment as a design space that can be engaged and changed. The secret is in kinesthetic manipulation with content. It requires interaction and motivates learners to an active participation and holds their attention. It was and always will be exciting to walk through and interact with a three-dimensional environment [2].

\section{Online and offline learning}

With such a small device like VR headsets student can learn both with or without internet connection. They can enter 'a classroom' or perform any task offline, as a homework, they can come back to the passed lesson and review all the materials and cases that has been studied.

On the basis of what has been stated above, we can declare that VRbased technologies can drastically change methods of foreign language teaching.

Learning new vocabulary can become an interactive game where students can complete tasks that develop creativity and critical thinking. They can have a conversation with a native speaker from any part of the world and take a straw in London, New York, Paris or any other city.

In addition, there is a number of possibilities of using VR in learning foreign languages:

- training specific situations or role-play;

- sharing experience with the class and discussion;

- visualization of learned materials and vocabulary;

- interacting with native speakers from all over the world;

- modeling an environment similar to one where the target language is spoken.

Virtual Reality has a great potential of adopting into education process. It may be a challenging task but definitely worth it. In the field of higher education, use of VR, for now, can be expensive. However, VR technology has a number of obvious advantages over traditional teacher's aids and the prospects for its application are fully justified:

- VR can provide new alternate methods for presentation of educational materials. It can illustrate those materials more accurately, allowing observation from any angle.

- VR can duplicate a real life situation and place or create a completely new one, if needed. 
- VR can boost students' creative and critical thinking by making problem-solving decisions.

- VR can provide participant with an immediate feedback and motivate student to move on.

The above-mentioned benefits and ways of using VR technology let us assume that it should take place in education. This line of research is methodologically important for VR-based education development and experimental verification.

\title{
References:
}

1. Eichenberg, Christiane, ed. Virtual reality in psychological, medical and pedagogical applications. 2012. P. 3-35.

2. Johnson-Glenberg, Mina C. The Necessary Nine: Design Principles for Embodied VR and Active Stem Education. Learning in a Digital World. Springer, Singapore. 2019. P. 83-112.

3. Kamińska D., Sapiński T., Wiak S., Tikk T., Haamer R. E., Avots E., Anbarjafari G. Virtual reality and its applications in education: Survey. Information, № 10.2019 .20 p.

DOI https://doi.org/10.30525/978-9934-588-80-8-2.33

\section{MODERN ART PRACTICES AND METHODS OF WORKING WITH CHILDREN WITH SPECIAL EDUCATIONAL NEEDS}

\author{
Voronina H. L. \\ Candidate of Pedagogical Sciences, \\ Senior Lecturer at the Department of Human Growth and Development \\ Kharkiv Academy of Continuing Education \\ Churkina V. H. \\ Candidate of Art History, \\ Assistant Professor at the Department of Human Growth and Development \\ Kharkiv Academy of Continuing Education \\ Kharkov, Ukraine
}

The purpose of the article is to outline modern methods of working with children with special educational needs, which are artistic practices (public art).

Aesthetic principles of art pedagogy and art therapy, art practices (public art) and creative industries allow to attract the full potential of art and 